\title{
Proliferation-dependent differential regulation of the dolichol pathway genes in Saccharomyces cerevisiae
}

\author{
Kelley Lennon, Robert Pretel, Jared Kesselheim, \\ Stephan te Heesen ${ }^{1}$ and Maria A.Kukuruzinska ${ }^{2}$ \\ Departments of Oral Biology and Biochemistry, Center for Advanced \\ Bımedical Research, Boston Unwersity Medical Center, Boston, MA, USA \\ and 'Microbiology Institute, ETH Zurich, Switzerland \\ ${ }^{2}$ To whom correspondence should be addressed
}

The dolichol pathway serves in the synthesis of the dolichollinked oligosaccharide precursor for protein $N$-glycosylation. Recently, we reported that mRNAs of genes that function at the early steps in the dolichol pathway in yeast, ALG7, ALG1 and ALG2, were co-ordinately induced following growth stimulation of $\mathrm{G}_{0}$-arrested cells in a manner similar to that of the transcripts of the early growth response genes (Kukuruzinska,M.A. and Lennon,K. Glycobiology, 4, 437-443, 1994). To determine whether the entire dolichol pathway was co-ordinately regulated with growth, we examined the expression of genes functioning late in the pathway, including two genes encoding oligosaccharyltransferase subunits, at two critical control points in the $G_{1}$ phase of cell cycle: $G_{0} / G_{1}$ and START. We show that early in $G_{1}$, at the $G_{0} / G_{1}$ transition point, the late ALG genes and the two oligosaccharyltransferase-encoding genes examined were regulated co-ordinately with the early ALG genes: they were downregulated upon exit from the mitotic cell cycle into $G_{0}$, and they were induced following growth stimulation in the absence of de novo protein synthesis. All the dolichol pathway genes produced transcripts with short. half-lives that were rapidly stabilized in the presence of cycloheximide. In contrast, cell division arrest late in $\mathrm{G}_{1}$, at START, was accompanied by a selective downregulation of only the first dolichol pathway gene, ALG7, and not of the genes functioning later in the pathway. These results indicate that, depending on their position in $G_{1}$, cells either co-ordinately or differentially regulate the dolichol pathway genes.

Key words: $N$-glycosylation/proliferation/Saccharomyces cerevisiae

\section{Introduction}

The dolichol pathway of protein $N$-glycosylation comprises a number of genes (ALG genes) that function sequentially in a stepwise addition of monosaccharides to the dolichol carrier to produce the 14-sugar oligosaccharide precursor (Figure 1). The oligosaccharide is then transferred as a unit to the asparagine residues of polypeptides, within an Asn-X-Ser/Thr consensus sequence, in a reaction catalysed by the oligosaccharyltransferase (Komfeld and Kornfeld, 1985; Kukuruzinska et al., 1987; Herscovics and Orlean, 1993). The significance of the dolichol pathway is documented by the fact that the obligatory nature of protein $\mathrm{N}$-glycosylation resides in its initial steps
(Kukuruzinska et al., 1987). Of the initial glycosyltransferase genes cloned to date, those acting at the first (ALG7) (Kukuruzinska and Robbins, 1987), third (ALG1) (Albright and Robbins, 1990) and fifth (ALG2) (Jackson et al., 1993) steps in the pathway in yeast have been shown to be essential for viability. Although the precise function(s) and downstream genetic targets of $\mathrm{N}$-glycosylation have not been established, cumulative data indicate that the dolichol pathway plays a role in growth and proliferation. Specifically, deregulated expression of the first gene in the dolichol pathway, ALG7, has been shown to result in phenotypes reflecting defects in $G_{1} / S$ transition (Arnold and Tanner, 1982; Kukuruzinska and Lennon, 1995) and in an abnormal exit from the mitotic cycle into $G_{0}$ upon quiescence (Kukuruzinska and Lennon, 1995). In addition, mutations in either ALG1 or ALG2 genes cause cell cycle arrest in the $G_{1}$ phase (Klebl et al., 1984; Jackson et al., 1993). These data have suggested that $N$-glycosylation affects the proliferative capacity of yeast cells.

In an effort to further define the role of the dolichol pathway in cellular growth and proliferation, we have focused on characterizing the expression of its component genes in the $G_{1}$ phase of the cell cycle, a period during which control of proliferation takes place. Recently, we have shown that the early ALG genes are regulated at the $\mathrm{G}_{0} / \mathrm{G}_{1}$ transition point in a manner resembling that of mammalian early growth response genes (Hofbauer and Denhardt, 1991; Kukuruzinska and Lennon, 1994). Withdrawal of glucose from actively proliferating yeast cultures is accompanied by downregulation of early ALG gene expression at the mRNA level. The early ALG gene mRNAs are rapidly induced in quiescent cells upon stimulation to proliferate in the absence of de novo protein synthesis, suggesting that they play some role in mediating the transition from quiescence to proliferation. Consistent with the characteristics of the early growth response genes, mRNAs of the early ALG genes have very short half-lives, and they are rapidly stabilized by cycloheximide (Kukuruzinska and Lennon, 1994).

Transit through $G_{1}$ involves progression through a series of subphases, starting either from $G_{0}$ or from the previous cell cycle, and requires the co-ordinate action of $\mathrm{G}_{1}$ regulators that integrate different mitogenic and antiproliferative signals to the cell cycle machinery (Pardee, 1989). Two major control points have been defined as determinants of the rate of cell proliferation: early in $G_{1}$ at the $G_{0} / G_{1}$ transition point, and in late $G_{1}$, at START (restriction point in animal cells). In this study, we wanted to determine whether the late genes in the dolichol pathway, as well as the genes encoding two oligosaccharyltransferase subunits, were co-ordinately regulated with the early ALG genes at the $G_{0} / G_{1}$ transition point. In addition, we were interested to examine whether the dolichol pathway genes were regulated at the second point controlling the proliferative potential of cells, in late $\mathrm{G}_{1}$, at START. Utilizing recently isolated clones of genes that function late in the dolichol pathway, as 
CYTOSOL

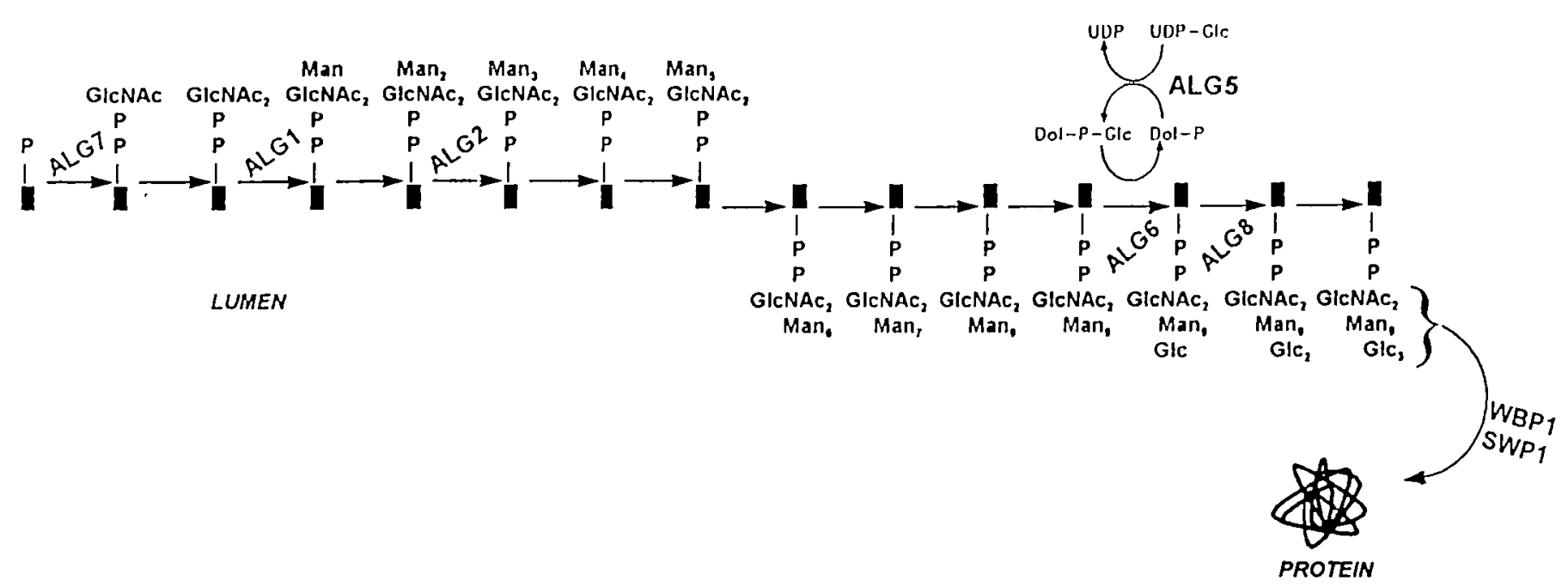

Fig. 1. Schematic representation of the dolichol pathway with genes investigated in this study. Synthesis of the oligosaccharide precursor for protein $\mathrm{N}$-glycosylation begins in the endoplasmic reticulum on the lipid carrier, dolichol. Through the sequential action of the dolichol pathway genes, monosaccharides are assembled on the dolichol carrier to produce the 14-sugar oligosaccharide precursor. The oligosaccharide is then transferred as a unit to the appropriate asparagine residues of polypeptides via the action of the oligosaccharyltransferase subunits. The steps at which specific genes function are shown. Arrows indicate the direction of synthesis of the oligosaccharide precursor.

Table I. Features of the dolichol pathway genes

\begin{tabular}{|c|c|c|c|c|c|}
\hline $\begin{array}{l}\text { Pathway } \\
\text { step no. }\end{array}$ & Gene & $\begin{array}{l}\text { Essentrality } \\
(+/-)\end{array}$ & $\begin{array}{l}\text { Open reading } \\
\text { frame }(\mathbf{k b})\end{array}$ & $\begin{array}{l}\text { Transcript } \\
\text { no. }\end{array}$ & $\begin{array}{l}\text { Transcript size } \\
\text { (kb) }\end{array}$ \\
\hline 1 & ALG7 & + & 1.34 & 2 & $\begin{array}{l}1.4 \\
1.6\end{array}$ \\
\hline 3 & ALG1 & + & 1.35 & 2 & $\begin{array}{l}1.8 \\
1.95\end{array}$ \\
\hline 5 & ALG2 & + & 1.6 & 1 & 1.7 \\
\hline 12 & ALG6 & - & 1.5 & 2 & $\begin{array}{l}1.6 \\
1.8\end{array}$ \\
\hline 13 & ALG8 & - & 1.8 & 1 & 2.1 \\
\hline aux' & ALG5 & - & 1 & 2 & $\begin{array}{l}1.1 \\
1.2\end{array}$ \\
\hline transfer ${ }^{b}$ & WBP1 & + & 1.3 & 2 & $\begin{array}{l}1.4 \\
1.5\end{array}$ \\
\hline & SWPI & + & 0.9 & 1 & 1.0 \\
\hline
\end{tabular}

'ALG5 acts in an auxiliary manner outside the dolichol pathway.

Oligosaccharyltransferase subunits.

well as two essential genes encoding oligosaccharyltransferase subunits (te Heesen et al., 1992, 1993; Kelleher and Gilmore, 1994), we show that all the dolichol pathway genes encode transcripts with short half-lives that are co-ordinately regulated at the $G_{0} / G_{1}$ transition point. In contrast, growth arrest in late $\mathrm{G}_{1}$, at START, results in a selective downregulation of only the first gene in the pathway, ALG7, indicating that the dolichol pathway genes are differentially regulated at two distinct substages in the $G_{1}$ phase of the cell cycle.

\section{Results}

Features of the late ALG and two oligosaccharyltransferase subunit genes

In an effort to initiate elucidation of the regulatory mechanism(s) governing gene expression in the dolichol pathway, we examined transcript complexities of its component genes. In the case of ALG7, the first gene in the dolichol pathway, the production of multiple transcripts allows for additional control levels (Kukuruzinska and Lennon, 1995). The sizes and transcript complexities of the genes acting late in the dolichol pathway, including two essential oligosaccharyltransferase subunit genes, WBP1 and SWP1, were determined by high-resolution RNA blotting assays (data not shown). Transcript sizes were estimated from semi-log plots of the distances mRNAs migrated in the gels versus their molecular weights and compared with mRNAs of the early ALG genes (Table I). Although all the genes examined produced mRNAs of similar size, ranging from 1 to $2 \mathrm{~kb}$, there was no correlation between transcript complexity and either essentiality or position at which a particular gene functioned in the pathway. For instance, the essential genes that act at the initial steps in the dolichol pathway, ALG7 and ALG1, belong to a category of complex transcriptional units (Kukuruzinska and Robbins, 1987; Albright and Robbins, 1990); similarly, WBP1, an essential oligosaccharyltransferase subunit gene, gave rise to two major transcripts 


\begin{tabular}{|c|c|c|c|c|c|}
\hline $\begin{array}{l}\text { Step } \\
\text { no. }\end{array}$ & Gene & $\begin{array}{l}\text { Transcript } \\
\text { size } \\
\text { (kb) }\end{array}$ & $\begin{array}{l}t_{1 / 2^{*}} \\
(\min )\end{array}$ & $\begin{array}{l}\text { Type of } \\
\text { decay }\end{array}$ & $\begin{array}{l}\text { Stabilized by } \\
\text { cycloheximide } \\
(+H)\end{array}$ \\
\hline 1 & ALG7 & $\begin{array}{l}1.4 \& \\
1.6\end{array}$ & $\begin{array}{l}2 \\
3\end{array}$ & $\begin{array}{l}\text { complex } \\
\text { complex }\end{array}$ & $\begin{array}{l}+ \\
+\end{array}$ \\
\hline 3 & ALGl & $\begin{array}{l}1.8 \& \\
1.95\end{array}$ & 2.5 & $\begin{array}{l}\text { complex } \\
\text { complex }\end{array}$ & + \\
\hline 5 & ALG2 & 1.7 & 3.5 & complex & + \\
\hline 12 & ALG6 & $\begin{array}{l}1.6 \& \\
1.8\end{array}$ & 3.2 & simple & + \\
\hline 13 & ALG8 & 2.1 & 2 & simple & + \\
\hline aux" & ALG5 & $\begin{array}{l}1.1 \& \\
1.2\end{array}$ & 3 & simple & + \\
\hline transfer & WBP1 & $\begin{array}{l}1.4 \& \\
1.5 \\
1.0\end{array}$ & $\begin{array}{r}21 \\
15 \\
6\end{array}$ & $\begin{array}{l}\text { simple } \\
\text { simple } \\
\text { simple }\end{array}$ & $\begin{array}{l}+ \\
+ \\
+\end{array}$ \\
\hline
\end{tabular}

-For the complex kinetics, values are given for the fast decaying components. ${ }^{b}$ ALG5 acts in an auxiliary manner outside the dolichol pathway.

cOligosaccharyltransferase subunits.

(Table I). Nonetheless, a non-essential gene acting late in the pathway, ALG6, also produced two transcripts. Likewise, ALG5, a non-essential gene acting in an auxiliary manner to the dolichol pathway, gave rise to two mRNAs. That essentiality did not correlate with transcript complexity was further supported by the fact that another essential oligosaccharide subunit gene, SWP1, was transcribed only into a single mRNA; one of the early essential dolichol pathway genes, ALG2, also gives rise to one transcript (Jackson et al., 1993). Since complex transcriptional patterns correlate with multiple regulatory controls, typical of genes whose products perform critical functions, the rationale for transcript complexity of the select dolichol pathway genes remains obscure at this stage.

\section{Stabilities of the late ALG, WBPI and SWPI gene mRNAs}

Our previous studies have shown that the early ALG genes give rise to highly unstable transcripts that display complex decay kinetics (Kukuruzinska and Lennon, 1994). To assess the stabilities of the late ALG and two oligosaccharyltransferase subunit gene mRNAs, transcript decay rates were determined in temperature-sensitive RNA polymerase II mutants after the shift to the non-permissive temperature (Nonet et al., 1987; Herrick et al., 1990; Kukuruzinska and Lennon, 1994). Based on sequential hybridizations of RNA blots, mRNA decay rates were calculated from the plots of the percentage of steady-state mRNA levels versus time after temperature shift (data not shown). The half-lives $\left(t_{1 / 2}\right)$ of the transcripts of the dolichol pathway genes are summarized in Table II. All of the ALG gene mRNAs displayed similar, rapid decay rates, with $t_{1 / 2}$ values of 2-3 min. SWP1, one of the oligosaccharyltransferase subunit genes, produced a transcript that also decayed rapidly, with a $t_{1 / 2}$ of $6 \mathrm{~min}$, while another oligosaccharyltransferase subunit gene, WBP1, gave rise to mRNAs with significantly longer $t_{1 / 2}$ values of 21 and $15 \mathrm{~min}$ for the 1.4 and $1.5 \mathrm{~kb}$ species, respectively (Table II).

Sequence analyses revealed AU-rich instability elements (Peltz and Jacobson, 1992; Beelman and Parker, 1995) in the coding and $3^{\prime}$ untranslated regions ( $3^{\prime}$ UTRs) of all the transcripts examined in this study (Figure 2), although no sequences responsible for conferring instability to MAT $\alpha 1$ transcript were found in any of these mRNAs (Caponigro et al., 1993). The longer half-lives of WBP1 transcripts compared to the ALG and SWP1 mRNAs may reflect the participation of as yet uncharacterized stabilizing sequences in WBPI mRNAs. Interestingly, the genes acting at the beginning of the dolichol pathway, ALG7, ALG1 and ALG2, gave rise to mRNAs that displayed complex decay kinetics, whereas those functioning later on in the pathway, and at the transfer of the mature oligosaccharide precursor to protein, gave rise to transcripts that exhibited single-component decay patterns.

Characteristic of growth response genes (Hofbauer and Denhardt, 1991; Peltz et al., 1991), the early ALG gene transcripts were shown to be rapidly stabilized after treatment of cells with cycloheximide (Kukuruzinska and Lennon, 1994). In a similar fashion, cycloheximide abrogated degradation of all the dolichol pathway and oligosaccharyltransferase gene transcripts (Table II). In fact, no degradation of any of the transcripts was apparent, even minutes after the temperature shift (data not shown).

\section{Expression of the late $A L G$ and two oligosaccharyltransferase} subunit genes at the $G_{0} / G_{1}$ transition point

In order to determine whether the late dolichol pathway and two oligosaccharyltransferase subunit genes exhibited coordinate growth-dependent induction with the early ALG genes (Kukuruzinska and Lennon, 1994), we examined their steadystate transcript levels following release from growth arrest (Figure 3). After $4 \mathrm{~h}$ of glucose deprivation $\left(t_{0}\right)$, mRNAs were virtually undetectable for all genes examined, indicating downregulation of their transcripts upon exit into $G_{0}$. Within $15 \mathrm{~min}$ of glucose addition $\left(G_{15}\right)$, however, and similar to the early ALG gene mRNAs, transcript abundances of the late ALG and two oligosaccharyltransferase subunit genes increased significantly. After 120 min of glucose stimulation $\left(\mathrm{G}_{120}\right)$, WBP1 and SWP1 transcript levels began to decline, like the early ALG gene mRNAs, suggesting periodic regulation of their abundance. In contrast, accumulation of the late ALG genes' mRNAs continued to increase even $120 \mathrm{~min}$ followirig addition of glucose. The differences in the relative mRNA levels following growth stimulation may reflect differential regulation of these genes during the cell cycle.

All the dolichol pathway and the two oligosaccharyltransferase subunit genes were superinduced by cycloheximide following stimulation to proliferate $\left[(G+C)_{15},(G+C)_{120}\right]$, 
ALG7

\begin{tabular}{|c|c|c|}
\hline 234 & CAGUUUAUUUAUUUGUAAOG & 253 \\
\hline 238 & UUAUUUADUUGUAAOGUOCA & 257 \\
\hline 435 & CUGADgAUUUAUUUGA DUOA & 454 \\
\hline 439 & UGA UUUAUUUGAUUDACGUO & 458 \\
\hline 960 & AADUDUAUUUAUUCAUGUCC & 979 \\
\hline 1349 & AAGADUAUQDAUUGGAUGUO & 1368 \\
\hline 1406 & AUAADUAUUUAQDUADCGA & 1425 \\
\hline
\end{tabular}

ALG1

469 CUAADUADUgADUGGCACAA 620 GGAARUADUUAAUDCAAAGC

1244 AUGCDGADUUADACCAAAAA

1396 ACUCDUUDUUADACAGUOAC

488

639

1263

1415

ALG2

\begin{tabular}{|c|c|}
\hline 225 & రCGUणUपणUणADQGणUणUCG \\
\hline 257 & AGCUUUAUUUAGUDADUCAA \\
\hline 261 & UUAUUUAGUUAणUCAAUUGA \\
\hline 265 & UUAGUUAUUCAAUUGAUCCU \\
\hline 750 & DAAGUUAGUUAWUUGCGGUG \\
\hline 36 & AUAADUUUUUAUUACUCACU \\
\hline & CAADUAADUDADACUGCCAD \\
\hline
\end{tabular}

244

276

280

284

769

1655

1705

ALG6

1570 AAGADUAUUUCAACUCUOAA

1589

ALG8

1450 UGUADaADUUAUUUGCCGC 1698 GUGGUUADRDAAUUUGACG 1776 AAAADUAUUOAUAUAUGAAO 1803 AGAARUAUOUAUUGUACAUO

ALG5

\begin{tabular}{|c|c|c|}
\hline 74 & CACDgRADUUADUGGOCDA & 93 \\
\hline 86 & రGGU दDADUUADUUUCGCAD & 105 \\
\hline 962 & 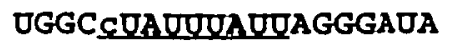 & 981 \\
\hline 1007 & 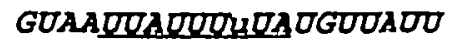 & 1026 \\
\hline 2106 & DOGCWUAOUUZUUOUOGAAA & 1125 \\
\hline
\end{tabular}

WPB1

\begin{tabular}{|c|c|}
\hline 122 & CAGUC्DAणUUANAAGAరCUA \\
\hline 865 & MAAGQUAUUUAUUCUGOAGG \\
\hline 31 & AUAADUCUUDADAAAUGGCU \\
\hline 36. & GUGUUUAUUUADAOUOUUUG \\
\hline
\end{tabular}

141

984

1333

1380

\section{SWP 1}

\section{CACCUQAOUGADAGGCUOAC}

Fig. 2. Location of instability elements in the coding and $3^{\prime}$ UTRs of the dolichol pathway and oligosaccharyltransferase gene transcripts. AU-rich instability sequences are underlined; italics indicate sequences occurring in the $3^{\prime}$ UTRs; lower-case letters show mismatches from the consensus sequence. Numbers reflect nucleotide position from the AUG codon.

indicating that their mRNAs increased in abundance in the absence of de novo protein synthesis. These data and the rapid kinetics of induction of these genes suggest that the dolichol pathway and two oligosaccharyltransferase subunit genes are co-ordinately regulated with growth. The observed synergistic effect of glucose and cycloheximide $\left[(G+C)_{15},(G+C)_{120}\right]$ indicates that this co-ordinate regulation occurs at more than one level (Kukuruzinska and Lennon, 1994).

To prove that the observed growth induction of the dolichol pathway and oligosaccharyltransferase subunit genes occurred early in $G_{1}$, we examined these genes' $m R N A$ levels after glucose stimulation in the presence of $\alpha$-factor that arrests cells in late $G_{1}$, at START (Throm and Duntze, 1970; Thorner, 1980). Transcripts of all the dolichol pathway and oligosaccharyltransferase subunit genes became visible within $3 \mathrm{~min}$ of glucose addition to $\mathrm{G}_{0}$-arrested cells, and their levels increased progressively over $20 \mathrm{~min}$; this increase in mRNA abundance occurred even in the presence of $\alpha$-factor, indicating that it took place prior to the performance of START (Figure 4). As expected, mRNA levels of the $\alpha$-factor inducible gene, FUS 1 (McCaffrey et al., 1987), were rapidly upregulated following glucose addition in the presence of the pheromone, reaching peak values at $6 \mathrm{~min}$ (Figure 4). It should be emphasized that the bar graph values represent the relative intensities of transcripts for each gene examined, and not the absolute level of expression. Taken together, these data indicate that growthrelated induction of the dolichol pathway genes occurs in an early substage of $\mathrm{G}_{1}$, and that it represents the primary genomic response to growth stimulation.

Effect of cell cycle arrest at START on the expression of the dolichol pathway and two oligosaccharyltransferase subunit genes

To determine the effect of cell cycle arrest in late $G_{1}$, at START, on the expression of the dolichol pathway genes, exponentially growing asynchronous wild-type cells were treated with $\alpha$-factor, and levels of ALG and oligosaccharyltransferase gene transcripts were assessed with RNA blotting assays. A decrease in ALG7 mRNA levels was already detected within $1 \mathrm{~h}$ of $\alpha$-factor addition; after one generation time ( $2.5 \mathrm{~h})$, a period necessary for $\alpha$-factor-specific cell cycle arrest and morphological changes, ALG7 transcript abundance declined to less than half of its initial steady-state level (Figure 5). Analyses of the genes acting downstream from ALG7 in the dolichol pathway, including two oligosaccharyltransferase subunit genes, showed that ALG7 was the only dolichol pathway gene that was downregulated in response to START arrest. Specifically, ALG1, WBP1 and SWP1 showed some induction upon treatment with $\alpha$-factor, while transcripts of ALG2, ALG6, ALG8 and ALG5 were unaffected in their abundance in response to the pheromone. As expected, levels of the $\alpha$-factor-inducible FUS1 mRNA increased dramatically during the first hour of pheromone treatment (Figure 5).

On a molecular level, $\alpha$-factor response in a cells is mediated by the pheromone response element (PRE), TGAAACA, with two copies of the PRE box, in either orientation, being required for response (Kronstad et al., 1987; Sengupta and Cochran, 1990). Sequence analyses of the $5^{\prime}$ non-coding regions of ALG7, ALG2, ALG6, ALG5, WBP1 and SWP1 genes revealed that they contained multiple copies of the PRE box (Figure 6). In contrast, the available sequence data for ALG1 and ALG8 genes disclosed only single copies of the PRE box in their $5^{\prime}$ non-coding regions. Additional sequence information will be necessary to ascertain the presence of other $\alpha$-factor response elements in the $5^{\prime}$ noncoding regions of all of these genes. The significance of PRE boxes in the $5^{\prime}$ non-coding regions of the dolichol pathway and 


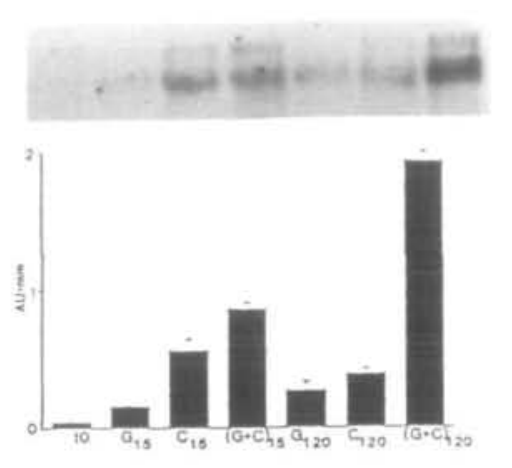

ALG6
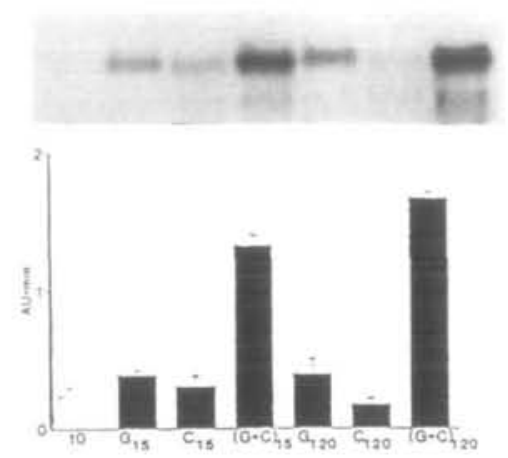

ALG8

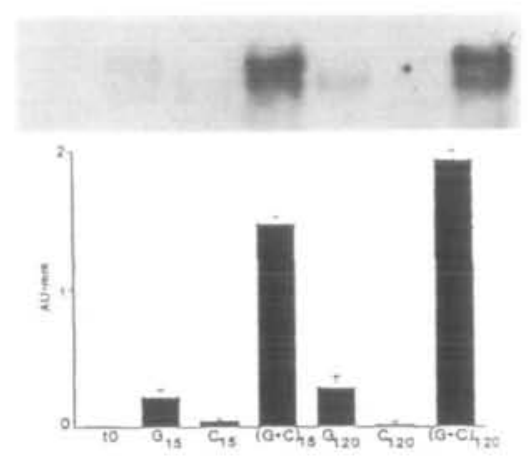

ALG5

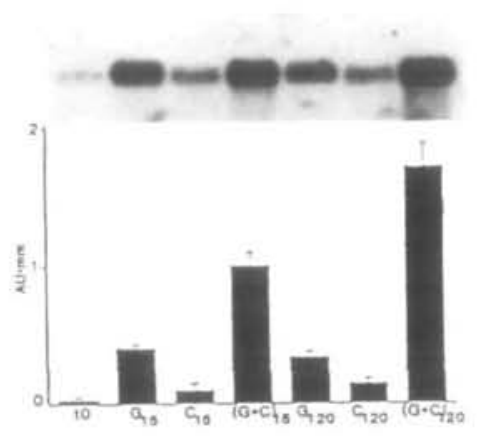

WBP1

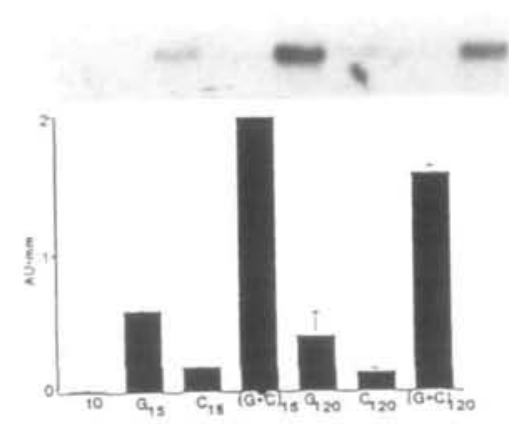

SWP1

Fig. 3. Growth induction of the late $A L G$ and oligosaccharyltransferase genes at the $G_{0} / G_{1}$ transition point. Wild-type, $S 288 C$ cells were glucose-starved for $4 \mathrm{~h}$ $\left(t_{0}\right)$ and then stimulated to proliferate by the addition of glucose to $2 \%\left(\mathrm{G}_{15}, \mathrm{G}_{120}\right)$, cycloheximide to $25 \mu \mathrm{g} / \mathrm{ml}\left(\mathrm{C}_{15}, \mathrm{C}_{120}\right)$, or both $\left[(\mathrm{G}+\mathrm{C})_{15},(\mathrm{G}+\mathrm{C})_{120}\right] . \mathrm{Cell}_{\mathrm{s}}$ were then incubated at $30^{\circ} \mathrm{C}$ for 15 and $120 \mathrm{~min}, 15 \mathrm{ml}$ aliquots were removed and total RNAs were isolated. Equal amounts ( $8 \mu \mathrm{g}$ ) of total RNAs were subjected to electrophoresis on $2 \%$ agarose-6\% formaldehyde gels, transferred to GeneScreen ${ }^{\text {TM }}$ membranes, and then sequentially hybridized with ${ }^{32} \mathrm{P}-$ labelled probes for the late ALG and two oligosaccharyltransferase subunit genes (insets). Membranes were exposed to X-ray film, with intensifying screens, at $-70^{\circ} \mathrm{C}$. Band intensities were quantified using the LKB laser densitometer and GelScan software (Pharmacia); multiple exposures of membranes were used to determine accurate relative intensities. Data were corrected for variations in gel loading and plotted as arbitrary absorbance units (AU*mm) versus time. Each data point represents an average of three determinations; the SEM is indicated. The values displayed were adjusted to the same scale and represent the relative abundances of transcripts for each gene, but do not reflect the absolute level of expression for each gene.

oligosaccharyltransferase subunit genes is not clear, however, since not all of these genes responded to $\alpha$-factor treatment (Figure 5). All the dolichol pathway and two oligosaccharyltransferase subunit genes contained multiple TATA elements in their promoter regions. Since constitutively expressed yeast genes frequently contain TATA-less promoters, the presence of TATA boxes in the ALG genes may reflect regulated expression on the level of transcript initiation. Sequence analyses also revealed the presence of cell cycle regulatory boxes, GCGAAA (Osley et al., 1986), in the 5' non-coding regions of ALG7 and ALG5 genes.

\section{Discussion}

The data presented here show that the genes that function in the synthesis of the oligosaccharide precursor for protein $N$-glycosylation in yeast are differentially regulated in response to growth arrest at two distinct control points in the $G_{1}$ phase of cell cycle: early in $G_{1}$, when cells exit into $G_{0}$, and late in $G_{1}$, at START. Both growth arrests, consequences of the integration of anti-proliferative signals with the cell cycle machinery, prevent cell division under unfavourable conditions.

Our results indicate that the late ALG genes examined to date, and the oligosaccharyltransferase subunit genes, are downregulated upon exit of the cells into $G_{0}$ following glucose withdrawal (Figure 3). Although the kinetics of their downregulation may differ, most of the transcripts of the dolichol pathway genes were undetectable within $1 \mathrm{~h}$ following nutrient removal (data not shown). Likewise, growth stimulation of $\mathrm{G}_{0}$-arrested yeast cultures led to a rapid induction of the dolichol pathway genes, whose transcripts already became detectable 3 min following addition of glucose (Figure 4). For all the ALG genes, this induction occurred in the absence of de novo protein synthesis, indicating that the dolichol pathway genes are a primary component of the genetic programme for growth.

Because all the ALG gene mRNAs were superinduced in the presence of cycloheximide, they are likely to be regulated at more than one level. Similar to the early ALG genes (Kukuruzinska and Lennon, 1994), the genes functioning at the later steps in the dolichol pathway gave rise to rapidly degraded transcripts, whose common feature was that they were 


\section{K.Lennon et al.}
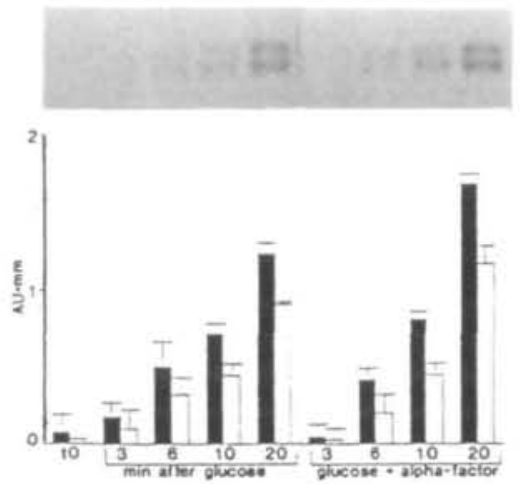

ALG7

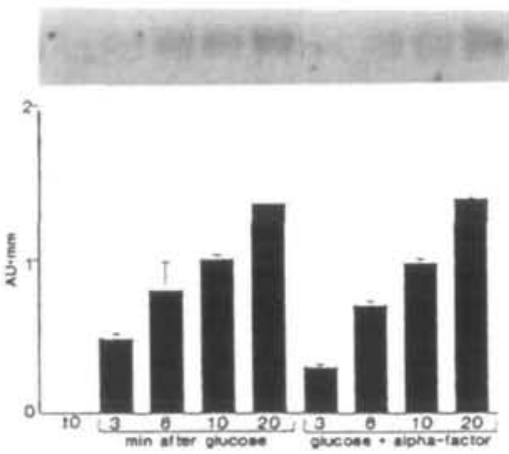

ALG6

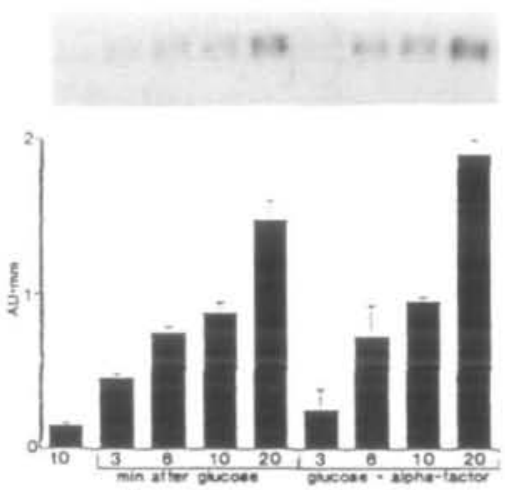

WBP1
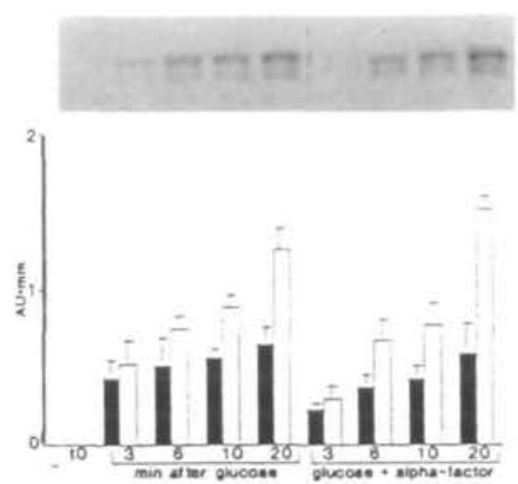

ALG1
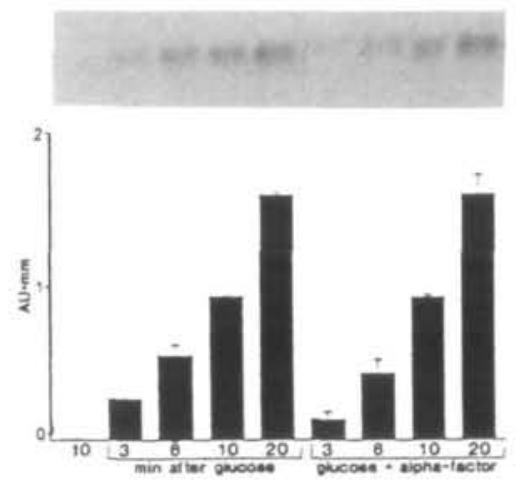

ALG8
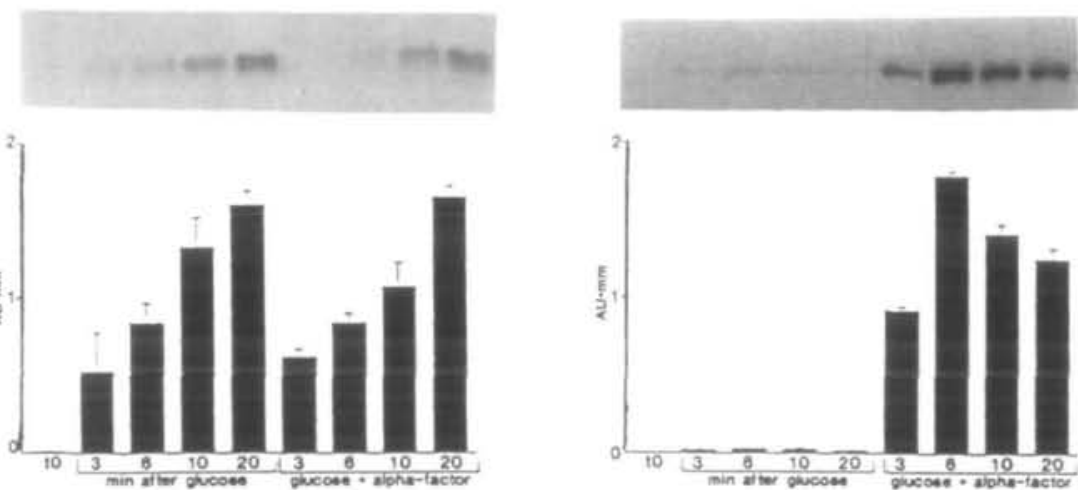

\section{FUS1}

Fig. 4. Effect of $\alpha$-factor on growth induction of the dolichol pathway and oligosaccharyltransferase genes. Asynchronous wild-type GR2 cells were grown to mid-exponential phase $\left(A_{660}=1.2\right)$, glucose deprived for $4 \mathrm{~h}$ and divided into two flasks. To one-half, glucose was added to $2 \%$; to the second half, glucose and $\alpha$-factor were added to $2 \%$ and $10 \mu \mathrm{M}$, respectively. Cells were then incubated at $30^{\circ} \mathrm{C}$; at the indicated times, $50 \mathrm{ml}$ aliquots were removed and used for RNA isolations and analyses as described in Figure 3. The blot was sequentially hybridized with radiolabelled probes of dolichol pathway genes, ALG7, ALG1, ALG2, ALG6, ALG8 and ALG5; two oligosaccharyltransferase subunit genes, WBP1 and SWP1; and the $\alpha$-factor-inducible FUS1 gene (insets). Membranes were exposed to X-ray film, with intensifying screens, at $-70^{\circ} \mathrm{C}$. Relative intensities of transcript bands were measured using an LKB laser densitometer with GelScan ${ }^{7 M}$ software (Pharmacia) for multiple exposures of the membranes. Values obtained were normalized for loading variations, and arbitrary absorbance units $\left(A U^{*} \mathrm{~mm}\right)$ were plotted versus time. Each data point represents one of three independent determinations; the SEM is indicated. For ALG7 results, the solid bars represent the $1.4 \mathrm{~kb}$ mRNAs and the open bars depict $1.6 \mathrm{~kb}$ transcript levels. For ALG1 results, the solid bars depict the $1.8 \mathrm{~kb}$ transcripts, while the open bars indicate the $1.95 \mathrm{~kb}$ mRNAs. The bar graph values were adjusted to the same scale and indicate the relative abundances of mRNAs at each time point, not the absolute levels of gene expression. 

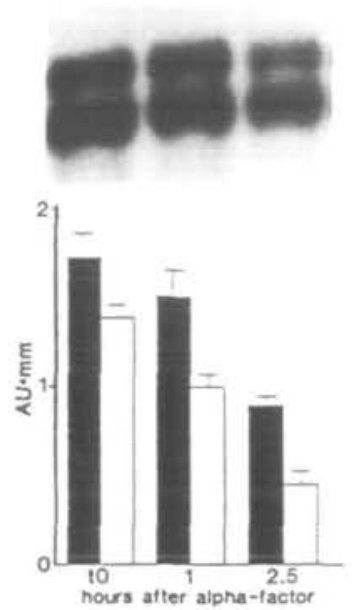

ALG7
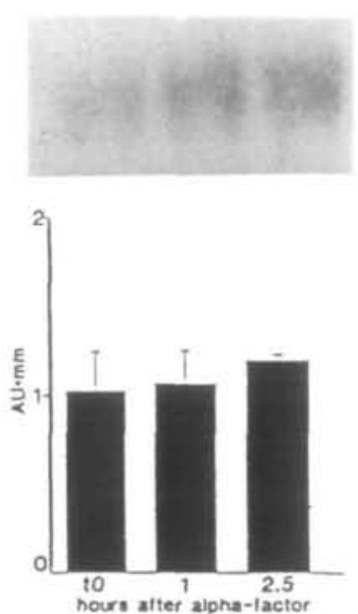

ALG6
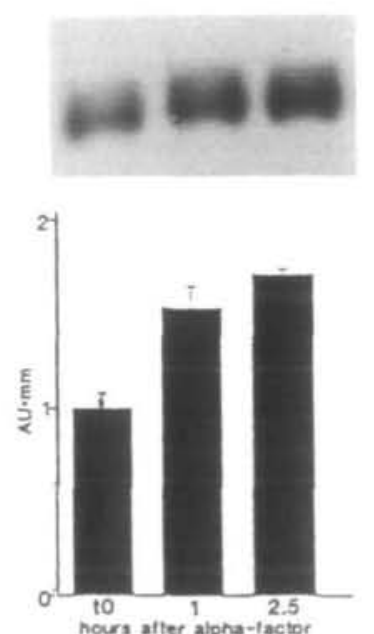

WBP1
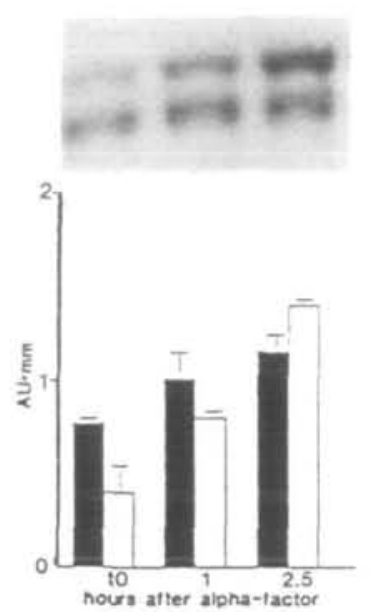

ALG1
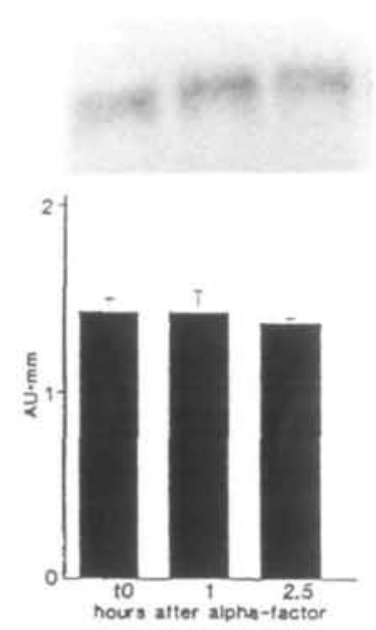

ALG8
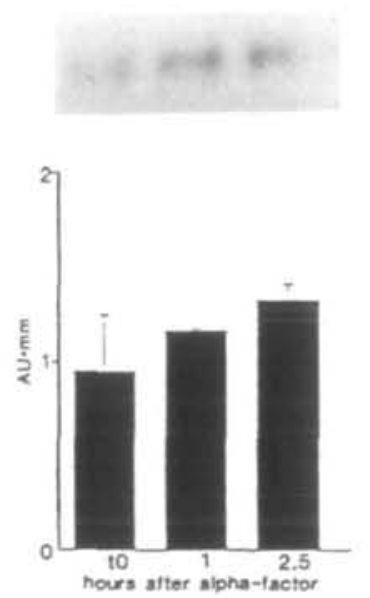

SWP1

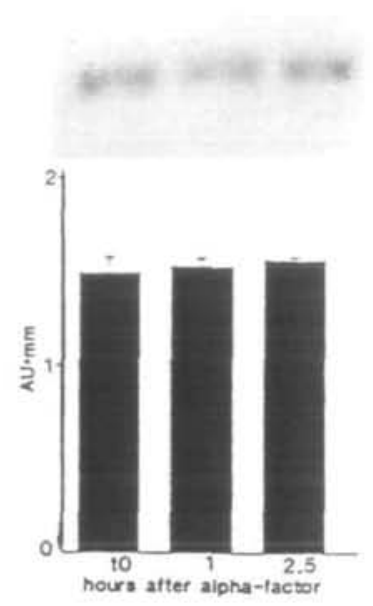

ALG2
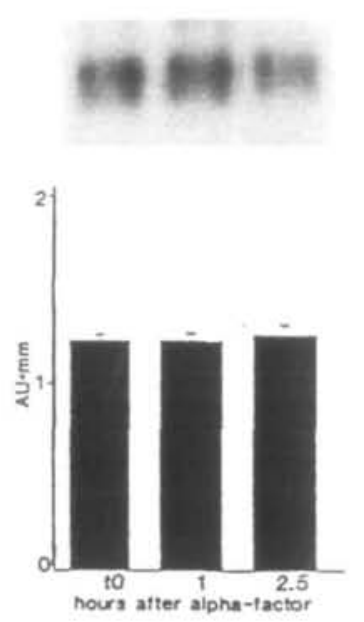

ALG5
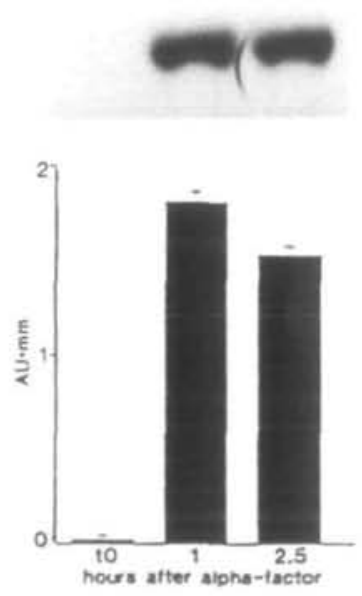

FUS1

Fig. 5. Expression of the dolichol pathway genes, two oligosaccharyltransferase subunit genes and FUSI following $\alpha$-factor-induced arrest at START. Asynchronous, wild-type GR2 cells were grown in SD media to $A_{60 n}=1.2 ; \alpha$-factor was then added to a final concentration of $10 \mu \mathrm{M}$. At the indicated times, $50 \mathrm{ml}$ aliquots were removed, total RNAs were isolated, and RNA blotting assays were performed as described in Figure 3 . Blots were sequentially hybridized with the ${ }^{32}$ P-labelled probes of the following genes: ALG7, ALG1, ALG2, ALG6, ALG8, ALG5, WBP1, SWP1 and FUS1. Membranes were exposed to X-ray film and intensifying screens at $-70^{\circ} \mathrm{C}$. Routinely, several exposures were used to obtain accurate assessment of each gene's expression. Values were corrected for differences in gel loading and arbitrary absorbance units ( $\mathrm{AU}^{*} \mathrm{~mm}$ ) versus time were plotted. Each data point represents four independent determinations, with the SEM indicated. For ALG7 results, the solid, black bars represent the J.4 kb transcripts, whereas the lighter bars indicate the 1.6 kb transcript; for ALG1 results, the solid, black bars show the $1.8 \mathrm{~kb}$ transcript and the lighter bars depict the $1.95 \mathrm{~kb}$ mRA. The bar graph values were adjusted to the same scale and represent the relative intensities of mRNAs at each time point, but do not reflect the absolute level of expression for each gene. 
ALG7

- 440 AAAATATtAAACAGTTGAAA -421

-72 TAACTGTGAAAATGTAAAT -53

- 20 GGTAACAAMAGTAGACTAT - 1

ALG1

-172 TGTTGCTRAMACAMGTCAA - 153

- 168 GCTAAAMCAAGGTCAATCCA - 149

ALG2

-825 ATTGGCACAAACTTTATATG -806

- 530 GCAMATGAMARACACANAT - 511

-522 AANAACACAAAETCTAATGG -503

-386 TAGACCTGAtACACCGTGTG -367

- 356 CTAGAATGAACAGGGCGGC -337

- 319 TGACAGTAAAACAMATCTT - 300

- 315 AGTAAAACAMAATCTTGGGC -296

- 122 CGAACAACAMAaTAAATGAT - 103

ALG6

- 529 AACTGTACAATGTCAGTCAG - 510

- 155 ATATCTItAMACATGAAATT -136

ALG8

-392 TGAATITGAAACGAGGCTCT -373

ALG5

- 447 CCACCTPGNAACETTCTTT

-427 TTCCATTGMARATTAGATG

- 353 ACAAGTCCAMAGTCAAGTGT

- 339 AAGTGTACAEAGTTATCCTA

$-202$

TTCGAAMCAAAGTGTANACA

AATTACACAAAGCACAACAA

WBP 1

-336 CTGTCANAAARGTGATGAA

- 142 TACGCCTGAANAATACANA

- 133 AAAATATCAAACACGCTTCT

$-73$

TTGGTTALAAAGTTGAATAC

SWP 1

$\begin{array}{lll}-440 & \text { CCTTCTIGAAAAAAGTCCTC } & -421 \\ -437 & \text { TCTTGAAEAAAGTCCTCGAC } & -418 \\ -425 & \text { TCCTCGACAAMaTGGCCCTA } & -406\end{array}$

Fig. 6. Analysis of functional sequence elements in the 5' UTRs of the dolichol pathway and oligosaccharyltransferase subunıt genes. Pheromone response elements, PRE boxes (Kronstad et al., 1987; Sengupta and Cochran, 1990), in forward (underlined) and reverse (double underlined) orientations are indicated. One mismatch was permitted except for the A in position 5 (Kronstad et al., 1987); lower-case letters depict mismatches in the consensus sequence. Overlapping PRE boxes are italicized. Numbers reflect nucleotide position in the $5^{\prime}$ non-coding region, with $A$ of the ATG codon designated as 1 .

stabilized in the presence of a protein synthesis inhibitor. It is possible that degradation of the transcripts of the dolichol pathway genes is coupled to translation, although it may reflect a requirement for an unstable nuclease(s). Interestingly, WBPI mRNAs had significantly longer decay times compared to the other genes examined; based on the stability phenotypes of mRNAs in yeast, the WBP1 transcripts can be placed in the category of moderately stable mRNAs (Herrick et al., 1990).

The majority of the dolichol pathway genes, therefore, display characteristics of early growth response genes. That the entire dolichol pathway is turned on once cells receive a signal to proliferate may reflect the requirement for the synthesis of membranous structures necessary for growth, or for the modification of critical transcription factors, or both. Accordingly, the decision to downregulate the ALG genes in $G_{0}$ may be indicative of the overall low requirement for $N$-glycosylation in quiescent cells. The co-ordinate down- and upregulation of the ALG genes at the $G_{0} / G_{1}$ transition point may involve common cis-elements and/or trans-acting factors. Searches for shared motifs in the $5^{\prime}$ UTRs of the ALG genes have revealed the presence of possible $\alpha$-factor response elements (Kronstad et al., 1987; Sengupta and Cochran, 1990); regions homologous to elements that confer periodic transcription (Osley et al., 1986) were also present in the promoter regions of ALG7 and ALG5, although their significance remains unclear. At this time, little is known about the existence of trans-acting factors that may be involved in selective repression or activation of the ALG genes.

Interestingly, our data also show that the arrest of cell division later in $G_{1}$, at START, has diverse effects on the mRNA levels of the dolichol pathway genes. Arrest at START led to a downregulation of only ALG7 mRNA abundance; the transcripts of the ALGl gene were somewhat upregulated, while the abundance of mRNAs of genes functioning further downstream in the dolichol pathway, ALG2, ALG6 and ALG8, did not seem to be affected to a significant extent. Similar to ALG1, mRNAs of the oligosaccharyltransferase subunit genes, WBP1 and SWP1, were also upregulated. Differential response to START arrest suggests that, in addition to sharing sequences and possibly trans-acting factors that govem co-operative response to growth stimulation, other regulatory mechanism(s) must be involved in the specific suppression of ALG7 and upregulation of ALGI, WBP1 and SWP1 genes.

Downregulation of ALG7 at START is significant and necessary for cell cycle arrest in late $G_{1}$. Our recent studies indicate that alg 7 mutants with deregulated ALG7 expression (Kukuruzinska and Lennon, 1995) do not arrest at START as effectively as wild-type cells. Accordingly, induction of the $\alpha$-factor-specific FUSI transcript follows an aberrant time course in the alg 7 mutants, suggesting that ALG7 plays a role in the pheromone response pathway leading to START arrest (Pretel et al., 1995). Taken together, these data indicate that growth arrest in late $G_{1}$ requires downregulation of ALG7 expression, and not of the remaining dolichol pathway genes. That ALG7, the gene functioning at the first committed step in the $N$-glycosylation pathway, is selectively regulated supports our previous work showing that partial inhibition of ALG7 expression results in lower $N$-glycosylation and secretion of proteins in Xenopus oocytes (Kukuruzinska et al., 1994), and deregulation of ALG7 expression in yeast gives rise to a plethora of phenotypes displaying defects in cell cycle progression and $\mathrm{G}_{0}$ arrest (Kukuruzinska and Lennon, 1995). This argues that, at least in some cases, ALG7 may regulate the flux through the dolichol pathway, or function like a 'pacemaker' for the genes located downstream from it in the pathway.

It should be emphasized that our studies focus on the regulation of the dolichol pathway genes at two critical checkpoints in $G_{1}$ that determine the proliferative capacity of cells. Similar to the mammalian c-myc gene (Hofbauer and Denhardt, 1991), but unlike the majority of immediate early growth response genes, the peak expression of the early ALG genes occurs soon after growth stimulation, and their mRNAs are continuously present at appreciable levels throughout the cell cycle. Under conditions supportive of continued cycling, the levels of the 
mRNAs of the early dolichol pathway genes reach peak values soon after entry into the $S$ phase (B.Benton and F.Cross, personal communication; M.A.Kukuruzinska and A.Bird, unpublished data).

Previously, we suggested that the growth response characteristics of the early ALG genes reflected a generalized requirement for $N$-glycosylation to modulate various transcriptional and metabolic processes that, in turn, affect the rate of mass accumulation (Kukuruzinska and Lennon, 1994). Somewhat more specific insight has recently been obtained regarding the role of $\mathrm{N}$-glycosylation in the progression through START: inviable alg $1 \operatorname{cln} 1 \operatorname{cln} 2$ mutants can be rescued by overexpression of either CLN1 or CLN2, although their $N$-glycosylation defect persists. This suggests that a certain level of $\mathrm{N}$-glycosylation is required for driving cells through START, and overexpression of cyclins allows cells to pass through this checkpoint with lower $N$-glycosylation (B.Benton and F.Cross, personal communication). Alternatively, the requirement for correct $N$-glycosylation of a key target may be relaxed under conditions of cyclin overexpression.

From a pragmatic perspective, understanding of the control mechanisms that regulate expression of the dolichol pathway genes in response to physiological and environmental changes may prove important in predicting $a$ priori the extent of $N$-glycosylation. Current dogma is that, depending on the environmental and physiological state, cells regulate the activity of $N$-glycoproteins by modulating the pools of their $N$-glycoforms (Rademacher et al., 1988). Variations in a given $\mathrm{N}$-glycoprotein's $\mathrm{N}$-glycoforms arise as a consequence of changes in either the nature of carbohydrate moieties or the occupancy of glycosylation sequons, or both. On a molecular level, elaboration of $\mathrm{N}$-linked oligosaccharide structures has been shown to be dependent on the expression of the Golgilocalized glycosyltransferases and glycosidases (Paulson and Colley, 1989; Lowe, 1991; Moremen et al., 1994). Modulation of the number of $\mathrm{N}$-glycosylation sequons in response to physiological and environmental cues is likely to be determined earlier in the synthesis of $\mathrm{N}$-glycoproteins, at the level of the dolichol pathway. Determination of the molecular basis for the regulation of the dolichol pathway under distinct conditions of growth and differentiation, therefore, may prove useful in gaining knowledge of the molecular basis of $\mathrm{N}$-glycoprotein microheterogeneity.

Our studies document that the dolichol pathway plays a role in the primary genomic response to growth stimulation, and that it may function in the integration of mitogenic and antiproliferative signals. Further studies of the downstream genetic targets of $N$-glycosylation that are critical for proliferation will increase understanding of the precise role(s) this pathway plays in diverse processes involving signal transduction, differentiation, senescence, apoptosis and malignant transformation.

\section{Materials and methods}

\section{Strains, plasmids, media}

Yeast strains used in this study included GR2 (MATa ural hisl), provided by Gerald Johnston (Dalhousie University), and S288C (MAT $\alpha$ mal gal2). For mRNA stability studies, strain Y260 (MATa ura3-52 rpbl-l), containing a temperature-sensitive ( $t s$ ) mutation in RNA polymerase $\mathrm{H}$, was used as described before (Kukuruzinska and Lennon, 1994).

For studies of the expression of the late dolichol pathway ALG genes, clones of ALG5, ALG6 and ALG8 genes in YEp352 plasmids were used (te Heesen et al., 1994; Stagljar et al., 1994). Expression of oligosaccharyltransferase subunit genes was assessed using clones of WBP1 and SWP1 in pBluescript KS+ plasmids (te Heesen et al., 1991, 1992). The FUSl-containing plasmid, pSL589, was a gift from Benjamin Benton and Frederick Cross (Rockefeller University).

The minimal medium (SD) was yeast nitrogen base (without amino acids), supplemented with $2 \%$ glucose and $0.01 \%$ of the appropriate amino acids. For studies using $\alpha$-factor, the pheromone was added to $S D$ to a final concentration of $10 \mu \mathrm{M}$; cycloheximide was added to a final concentration of $25 \mu \mathrm{g} / \mathrm{ml}$.

\section{Culture conditions}

In order to determine the transcriptional patterns of the late ALG and oligosaccharyltransferase subunit genes, asynchronous wild-type GR2 cells were grown in SD with $2 \%$ glucose and $0.01 \%$ uracil and histidine at $30^{\circ} \mathrm{C} 10 \mathrm{~A}_{660}=$ 1.1. At this tıme, $50 \mathrm{ml}$ of cells were removed and used for RNA isolations. Both mRNA stability and glucose/cycloheximide induction studies were conducted as described previously (Kukuruzinska and Lennon, 1994).

For studies of growth induction at the $\mathrm{G}_{0} / \mathrm{G}_{1}$ transition point, asynchronous GR2 cultures were grown in minimal media containing $2 \%$ glucose to midexpontial phase $\left(A_{660}=1.2\right)$ and then growth arrested by glucose deprivation for $4 \mathrm{~h}$. Cultures were then split: to one-half, glucose was added to $2 \%$ final concentration; to the other half, glucose and $\alpha$-factor were added to final concentrations of $2 \%$ and $10 \mu \mathrm{M}$, respectively. At the indicated tımes, $50 \mathrm{ml}$ aliquots were removed and used for RNA isolations and analyses.

To examine the effect of cell cycle arrest in late $G_{1}$, at START, on the dolichol pathway and oligosaccharyltransferase subunit gene mRNAs, the mating pheromone $\alpha$-factor was used. Asynchronous wild-type GR2 cells were grown to $A_{660}=1.0$ in minimal media containing $2 \%$ glucose, and $\alpha$-factor was added to a final concentration of $10 \mu \mathrm{M}$. At the indicated times, aliquots of $50 \mathrm{ml}$ were removed and used for RNA ssolations and analyses.

RNA extractions and analyses

Total RNAs were isolated as described previously (Kukuruzinska and Robbins, 1987). The integrity of the RNAs was assessed by size separation on $1 \%$ agarose-6\% formaldehyde gels. For RNA blotting and analyses, RNAs were fractionated on $2 \%$ agarose-6\% formaldehyde denaturing gels and transferred to Genescreen (DuPont/NEN) membranes. mRNAs were detected by sequential hybridization of membranes with ${ }^{32} \mathrm{P}$-labelled, gene-specific, random primer-generated probes (Promega): an 800 bp Clal fragment for ALG7 (Kukuruzinska and Robbins, 1987), an 800 bp EcoRV restriction fragment for ALGl (Albright and Robbins, 1990), a 500 bp Accl restriction fragment for ALG2 (Jackson et al., 1993), a 1500 bp Spel-MscI fragment for ALG6, an 800 bp SmaI-KpnI fragment for ALG8 (Stagljar et al., 1994), a 900 bp Sacl-HindIIl fragment for ALG5 (te Heesen et al., 1994), a 650 bp BgII-XmnI fragment for SWPI (te Heesen et al, 1993), an 800 bp BamHI-Bgll fragment for WBPI (te Heesen et al., 1991) and a $1400 \mathrm{bp} \mathrm{HindIll-EcoRI} \mathrm{fragment}$ for FUSI (McCaffrey et al., 1987). Hybridizations were at high stringency. Autoradiography was performed at $-70^{\circ} \mathrm{C}$ with Reflections film and intensifying screens (NEN/DuPont).

\section{Quantufication of $m R N A$ levels}

The relatuve intensities of mRNA bands on autoradiographs were quantified using an LKB Ultrascan densitometer and Gelscan ${ }^{\text {TM }}$ software (Pharmacia). Multiple exposures of each membrane from individual hybridizalions were necessary to ensure linearity of signal and to obtain comparable numerical values. Adjustments for loading variations were made according to differences in band intensities of rRNAs stained with ethidium bromide $(0.5 \mu \mathrm{g} / \mathrm{ml})$. Abitrary absorbance unit $\left(\mathrm{AU}^{*} \mathrm{~mm}\right)$ values were plotted versus time using Harvand Graphics software, and the SEM was calculated for each time point. To allow cross-comparisons among different transcripts, relative values from autoradiographs were adjusted to the same scale; the bar graphs, therefore, do not reflect the absolute levels of the individual transcripts.

Sequence analyses

Searches for regulatory sequences were carried out using PCGene software (Intelligenetics).

\section{Acknowledgements}

We would like to thank Drs Markus Aebi and Barbara Jackson for critical reading of the manuscript. Many thanks to Drs Benjamin Benton and Frederick Cross for sharing with us unpublished results on $a l g l c \ln l c \ln 2$ mutants, and for providing us with the FUS l-containing, pSL589 plasmid. This work was supported in part by grant GM31318 to Phillips W.Robbins (MIT), and in part by grants GM41365, DE 1018 and KO4DE00362 to M.A.K. from the National Institutes of Health. 


\section{Abbreviations}

PRE, pheromone response element; $t s$, temperature sensitive; UTR, untranslated regions.

\section{References}

Albright,C.F. and Robbins,P.W. (1990) The sequence and transcript heterogeneity of the yeast gene ALGI, an essential mannosyltransferase involved in N-glycosylation. J. Biol. Chem., 265, 7042-7049.

Amold,E. and Tanner,W. (1982) An obligatory role of protein glycosylation in the life cycle of yeast cells. FEBS Lett., 148, 49-53.

Beelman,C.A. and Parker,R. (1995) Degradation of mRNA in eukaryotes. Cell, 81, 179-183.

Caponigro,G., Muhlrad,D. and Parker,R. (1993) A small segment of the MAT $\alpha 1$ transcript promotes mRNA decay in Saccharomyces cerevisiae: a stimulatory role for rare codons. Mol. Cell. Biol., 13, 5l4l-5l48.

Herrick,D., Parker,R. and Jacobson,A. (1990) Identification and comparison of stable and unstable mRNAs in Saccharomyces cerevisiae. Mol. Cell. Biol., 10, 2269-2284.

Herscovics,A. and Orlean,P. (1993) Glycoprotein biosynthesis in yeast. FASEB J., 7, 540-550

Hofbauer,R. and Denhardt,D.T. (1991) Cell cycle-regulated and proliferation stimulus-responsive genes. Crit. Rev. Euk. Gene Express, 1, 247-300.

Jackson,B.J., Kukuruzinska,M.A. and Robbins,P.W. (1993) Biosynthesis of asparagine-lınked oligosaccharides in Saccharomyces cerevisiae: the alg2 mutation. Glycobıology, 3, 357-364.

Kelleher,D.J. and Gilmore,R. (1994) The Saccharomyces cerevistae oligosaccharyltransferase is a protein complex composed of Wbplp, Swplp, and four additional polypeptides. J. Biol. Chem, 269, 12906-12917.

Klebl,F., Huffaker,T. and Tanner,W. (1984) A temperature-sensitive $N$-glycosylation mutant of Saccharomyces cerevisiae that behaves like a cell-cycle mutant. Exp. Cell Res., 150, 309-313.

Kornfeld,S. and Kornfeld,R. (1985) Assembly of asparagine-linked oligosaccharides. Annu. Rev. Biochem., 55, 631-664.

Kronstad,J.W., Holly.J.A. and MacKay,V.L. (1987) A yeast operator overlaps an upstream activation site. Cell, 50, 369-377.

Kukuruzinska,M.A. and Lennon,K. (1994) Growth-related coordinate regulation of the early $N$-glycosylation genes in yeast, Glycobiology, 4 , $437-443$.

Kukuruzinska,M.A. and Lennon,K. (1995) Diminished activity of the first $N$-glycosylation enzyme, dolichol-P-dependent $N$-acetylglucosamine-1-P transferase (GPT), gives nse to mutant phenotypes in yeast. Biochim. Biophys. Acta, 1247, 51-59.

Kukuruzinska,M.A. and Robbins,P.W. (1987) Protein glycosylation in yeast: transcript heterogeneity of the ALG7 gene. Proc. Natl Acad. Sci. USA, 84, 2145-2149.

Kukuruzinska,M.A., Bergh,M.L.E. and Jackson,B.J. (1987) Protein glycosylation in yeast. Annu. Rev. Biochem., 50, 555-583.

Kukuruzinska,M.A., Apekin,V., Lamkin,M.S., Hiltz,A., Rodriguez,A., Lin, C.C., Paz,M.A. and Oppenheim,F.G. (1994) Antisense RNA to the first

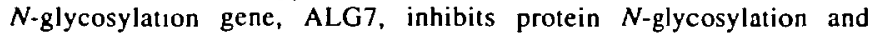
secretion by Xenopus oocytes. Biochem. Biophys. Res. Commun., 198, 1248-1254.

Lowe.J.B. (1991) Molecular cloning, expression and uses of mammalian glycosyltransferases. Cell Biol., 2, 289-307.

McCaffrey,G., Clay,F.J., Kelsay,K. and Sprague,G.F.J. (1987) Identification and regulation of a gene required for cell fusion durng mating of the yeast Saccharomyces cerevisiae. Mol. Cell. Biol., 7, 2680-2690.

Moremen,K.W., Trimble,R.B. and Herscovics,A. (1994) Glycosidases of the asparagine-linked oligosaccharide processing pathway. Glycobiology, 4, $113-125$.

Nonet,M., Scafe,J., Sexton,J. and Young,R. (1987) Eucaryotic RNA polymerase conditional mutant that rapidly ceases mRNA synthesis. Mol. Cell. Biol., 7, 1602-1611.

Osley,M.A., Gould,J., Kim,S., Kane,M. and Hereford,L. (1986) Identification of sequences in a yeast histone promoter involved in penodic transcription. Cell, 45, 537-544.

Pardee,A.B. (1989) $G_{1}$ events and regulation of cell proliferation. Science, 246, $603-608$.

Paulson,J.C. and Colley,K.J. (1989) Glycosyltransferases. J. Biol. Chem., 264, 17615-17618.

Peltz,S.W. and Jacobson,A. (1992) mRNA stability: in trans-it. Curr. Opin. Cell Biol., 4, 979-983.

Peltz,S.W., Brewer,G., Bemstein,P., Hart,P.A. and Ross J. (1991) Regulation of mRNA turnover in eukaryotic cells. Crit. Rev. Gene Express., 1, 99-126.
Pretel,R., Lennon,K., Bird,A. and Kukuruzinska,M.A. (1995) Expression of the first $N$-glycosylation gene in the dolichol pathway, ALG7, is regulated at two major control points in the $G_{1}$ phase of the Saccharomyces cerevisiae cell cycle. Exp. Cell Res., 219, 477-486.

Rademacher,T.W., Parekh,R.B. and Dwek,R.A. (1988) Glycobiology. Annu. Rev. Biochem., 57, 785-838.

Sengupta,P. and Cochran,B.H. (1990) The PRE and PQ box are functionally distinct yeast pheromone response elements. Mol. Cell. Biol., 10, 6809-6812.

Stagljar,I., te Heesen,S. and Aebi,M. (1994) New phenotype of mutations deficient in glucosylation of the lipid-linked oligosaccharide: cloning of the ALG8 locus. Proc. Natl Acad. Sci. USA, 91, 5977-5981.

te Heesen,S., Rauhut,R., Aebersold,R., Abelson,J., Aebi,M. and Clark,M.W. (1991) An essential $45 \mathrm{kDa}$ yeast transmembrane protein reacts with antinuclear pore antıbodies: purification of the protein, immunolocalization and cloning of the gene. Eur. J. Cell Biol., 56, 8-18.

te Heesen,S., Janetsky,B., Lehle,L. and Aebi,M. (1992) The yeast WBP1 is essential for oligosaccharyltransferase actıvity in vivo and in vitro. EMBO J., 6, 2017-2075

te Heesen,S., Knauer,R., Lehle,L. and Aebi,M. (1993) Yeast Wbplp and Swplp form a protein complex essential for oligosaccharyltransferase activity. EMBO J., 12, 279-284.

te Heesen,S., Lehle,L., Weissmann,A. and Aebı,M. (1994) Isolation of the ALG5 locus encoding the UDP-glucose:dolichyl-phosphate glycosyltransferase from Saccharomyces cerevisiae. Eur. J. Biochem., 224, 71-79.

ThomerJ. (1980) Intercellular interactions of the yeast Saccharomyces cerevisiae. In Leighton,T.J. and Loomis,W.A.Jr (eds), The Molecular Genetics of Development. Academic Press, New York, pp. 119-178.

Throm,E. and Duntze,W. (1970) Mating-type-dependent inhibition of deoxyribonucleic acid synthesis in Saccharomyces cerevisiae. J. Bacteriol., 104, $1388-1390$.

Received on Aprl 28, 1995; revised on June 5, 1995; accepted on June 8, 1995 